\title{
When anthropological considerations influence our attitude about the chin

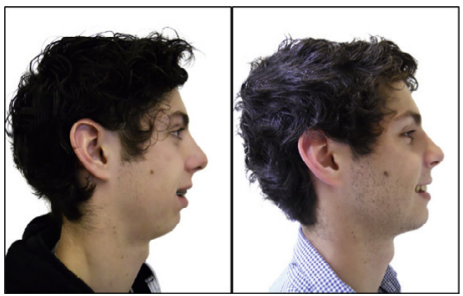 and orthognathic surgery
}

\author{
Mohamed EL-OKEILY, Masrour MAKAREMI
}

\begin{abstract}
The presence of a chin is a specific and unique feature of the human face that is absent from the face of our hominid ancestors and all other primates. A number of anthropologists have studied this anthropomorphic characteristic and elaborated various theories concerning its genesis and anatomical usefulness. Recent research based on the analysis of stress using the finite element method (FEM) seems to establish that the presence of the chin is a biomechanical consequence of skeletal and muscular equilibrium peculiar to the human face. This data is an important addition to our matrix of thoughts that influences our attitude concerning the chin and orthognathic surgery. In particular, whether or not a genioplasty is necessary, and whether it should be performed separately from orthognathic surgery or at the same time.
\end{abstract}

\section{KEY WORDS}

Genioplasty

Chin

Anthopology of the chin
Mentoplasty

Orthogathic surgery

\section{INTRODUCTION}

The surgical correction of facial dysplasias is an important and growing multidisciplinary field today. Case management of these dysplasias requires a treatment plan that involves close collaboration between the orthodontist and the maxillofacial 


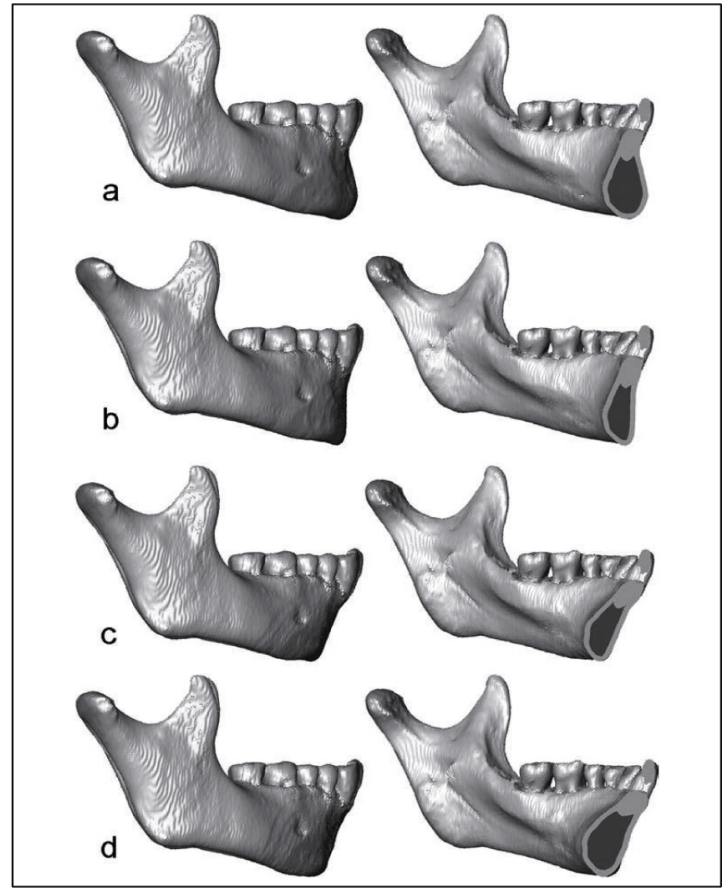

Different shapes of the chin, from the work of Gröning et al.

surgeon. This team, assisted by many practitioners, tries to address a two-fold objective that is both functional and morphological. The chin occupies a unique and important place in the treatment plan both from a morphological and functional perspective.

The chin (the trigonum mentale): whose base corresponds to the inferior border of the mandibule and whose summit reaches the median ridge of the mental symphysis, differentiates a central mammelon: the mental tubercle. The mental protuberance is beneath a depression: the mandibular curves, this protuberance causes the bony part of the chin to jut forward.

The chin is the paleontological criterion of choice to differentiate a modern mandible from a more primitive mandible. The appearance of the chin is still a highly topical issue.

This anthropological view of the chin has provided us with a new way of considering procedures when performing orthognathic surgery.

\section{WHY DO WE HAVE A CHIN?}

\section{Different theories}

The dental theory concerning the mental protuberance is the result of the appearance and deepening of the mandibular curve occurring at the junction of the two parts of the mandible: the underlying alveolar part and the underlying basal part. The formation of the anterior mandibular curve is made possible due to the lingual inclination of the roots of both the incisors and the canines and also because of the decrease in the length of the dental arch.

According to more current theories (Gröning et al.) the presence of the chin is a biomechanical consequence of the skeletal and muscular equilibrium that is unique to the human face. In particular, the stresses generated by masticatory muscles in the course of lateral and vertical movements that take place during the 


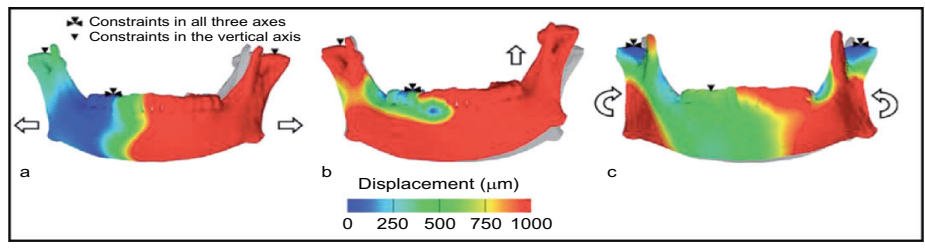

Stresses from pressure, from Gröning et al.

masticatory cycles seem to play a major role in the development of the chin.

Their conclusion comes as a result of a series of experiments made possible by implementing a powerful mathematical model based on finite elements and thus demonstrating that the appearance of the chin is a logical outcome for the mandible of anatomically modern humans

\section{GENIOPLASTY: TECHNICAL PRINCIPLES}

\section{General considerations}

Many techniques are described for performing a genioplasty. We will just provide a description of the standard technique or the current technique most widely used for genioplasty.

A genioplasty can be the only suggested treatment or it can represent one part of the treatment. It can also be the only surgical part of the therapeutic treatment plan of the patient or it can be one stage in a series of surgical procedures.

The indication for a genioplasty can modify the surgical technique and even change the timeframe chosen to perform it. because of the distribution of stresses from the masticatory muscles and occlusal pressures, but also because of the thinning of the skeleton of anatomically modern humans. Additionally, they demonstrated that the absence of the chin can be justified by the same mathematical models that justify cases of disequilibrium due to vertical excess or exaggerated robustness.

\section{Treating the mental symphysis}

The positioning of the patient must be done rigorously and must adhere to the standard practice of orthognathic surgery. The patient is in the head up position to reduce bleeding. The head is stabilized in a neutral position.

After an injection of Xylocaine with adrenaline also in order to reduce perioperative bleeding, the practitioner begins the intraoral procedure. The incision, in an inverted $V$ shape is made approximately $15 \mathrm{~mm}$ from the depth of the vestibule from 33 to 43.

The incision is made through the orbicular oris muscle of the lips then towards the periosteum that it 
pierces until stopped by osseous contact.

Next, the surgeon retracts a wide section of the symphysis thus making it possible to locate the mental nerves and to stop at the basal border.

\section{Osteotomy}

Marking the incision site as described by Obwegeser in 1957 is still widely used.

The shape, thickness and type of osteotomy will depend entirely on the indication.

The osteotomy must maintain a safe distance of at least five millimeters from the dental roots and from the mental nerves.

The incision site is marked with a round bur and/or piezoelectric device and then completed by using a reciprocating saw or a round bur with a larger diameter.

The angle of the osteotomy is particularly important since it will have a direct impact on the height of the lower third of the face.

The angle can be horizontal or oblique downwards and backwards. It can be single or multiple.

\section{Movements}

Various types of movements are possible once the symphysis has been freed and is mobile.

An advancement or forward sliding genioplasty, genioplasty for vertical lengthening or elongation, genioplasty for reduction (an intermediary bone fragment is removed) or impaction are all possibilities offered by this technique. We should also mention the "tenon and mortise" genioplasty involving a central osseous plate that guides the advancement. There is also the "jumping" genioplasty or overlapping, that consists in completely moving the fragment forward from the remaining symphysis.

$A$ recent variation described by Triaca A. called "chin wing", allows the surgeon to detach the chin from the lower border of the mandible (from the angle of the mandible on one side to the angle of the mandible on the other side) and makes it possible to additionally modify the position of the chin, to assess (independently from the movement of the dental portion of the mandible that is performed at the same time as a standard mandibular osteotomy) the relief of the line separating the face from the neck. This allows the practitioner to more accurately monitor the shape, the height and the width of the face.

\section{Attaching and closing}

Anchorage with steel wires, has been replaced more and more with rigid fixation for osteosynthesis that uses miniplates or compression screws. The preformed and pre-measured miniplates that are in a "crab shape" are currently used most of the time.

Next, the closing is achieved in two planes using absorbable sutures for muscle reinsertion that has to be performed with particular care.

A compression bandage is kept in place from 24 to 72 hours. 


\section{Other techniques and supplemental procedures}

Some supplemental procedures are possible and regularly implemented:

- Procedures for periodontal care: treatment for muscular fragility due to reinsertion of the muscles in a more inferior position on the bulbous portion of the chin. Some mucosal and/or gingivoplasties.

- Bone grafts: placed for the purpose of reinforcing incisor periradicular protection.
Other techniques have been used but they are still provisional:

- Chin prostheses: they are technically easier to use and present minor short-term side effects. However, they are often a source of infection, of secondary movement or osseous erosion in the long term.

- The cutaneous approach: may allow the practitioner to make small cartilaginous and/or bone grafts whose long term reliability and stability remain questionable.

- Bone abrasion: it used to be widely performed, but is now increasingly
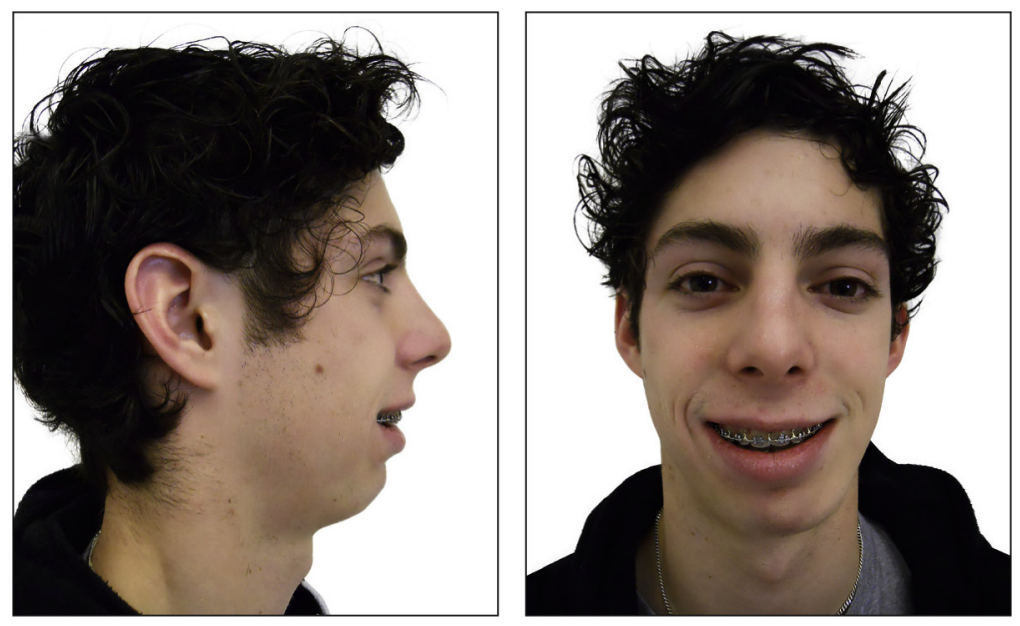

Geoffrey's case
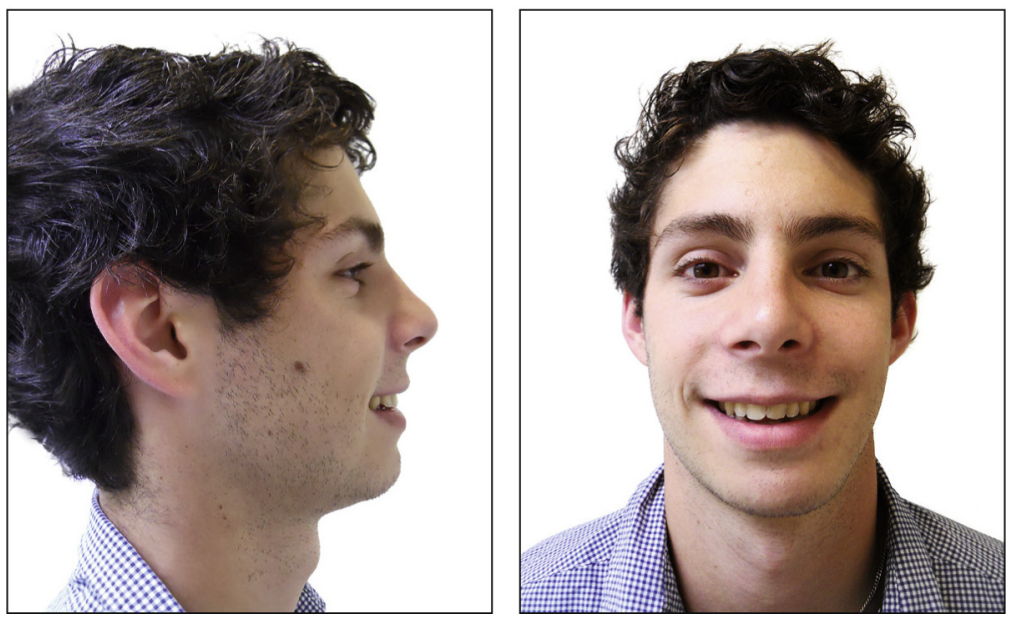
associated with "witch's chin" that is linked to muscular fat ptosis. This procedure is used only for limited and specific remodeling.

\section{Side effects and complications}

In general, the side effects of genioplasty are rather minor. After a 24 hour stay in the hospital, the discomfort is the result of localized edema and especially labio-mental numbness that can last several months.

The main complications are short term bleeding (rarely requiring drainage), secondary movement (very rare since the development of rigid fixation osteosynthesis) and bone resorption in cases of "jumping" or bone grafts.

However, there is no such thing as a "simple" surgical procedure, and the rare serious complications (hema-

\section{INDICATIONS}

From the very beginning of case management, we have to take into consideration the possible need for an additional surgical procedure for the chin.

The practitioner must have a dual perspective that includes both morphology and function.

The morphological perspective is subjective and the esthetic or standard cephalometric norms should be used with caution. There is certainly a place for a minor receded chin on a female face that can be charming just as a slightly receded chin can appear unsuited for some male faces. toma of the buccal floor, respiratory problems, etc.) make it essential to carefully consider the indications and the possible alternatives.

The period of patient adjustment to the esthetic modification generally requires more time than expected and in this case, considerable preliminary preparation.

The main "complication", if it can truly be considered a complication, is the postoperative dissatisfaction with the result of the procedure: undercorrection, overcorrection, inadequate correction...

Often, the recognition of this "imperfection" is delayed and can take place six months after the procedure. This is why we consider the indication for a genioplasty, as well as the timing of the procedure to be essential for determining an optimal treatment plan for the patient.

Therefore, we think that these norms can serve as a rough and basic framework for determining treatment and must be adapted case by case. What patients feel and what they expect are, in this case, fundamental and one of the difficulties will be to determine as precisely as possible the expectations of the patients and their own capacity to adjust to the change in their appearance.

As for the functional perspective, it includes a number of parameters:

- labial "competence" at rest and in motion with the occlusal component (on one hand maxillary and on 
the other mandibular) and the mentalis component.

- nasal or mouth breathing with possible obstacles to nasal breathing (cartilaginous and osseous nasal blockage, polyps, tonsils...)

- The tongue position at rest or in motion (swallowing inter alia), the volume and morphology of the tongue and the space available for the tongue.

- Mentalis musculature at rest and in motion.

- The possible presence of sleep apnea syndrome.
- The overall posture of the body and in particular a possible cervical protrusion.

- Labial tone and labial volume.

By using this dual morphological and functional perspective, the practitioner can immediately divide the patients into two separate groups:

- A "caricature" group whose indication for a genioplasty is immediately evident

- An "uncertain" group for whom it difficult to know in advance if the morphological and functional results will be inadequate and if their

In these 2 cases where a genioplasty was initially considered advisable, the choice to delay the decision for 8 months made it possible to more accurately determine the indication.
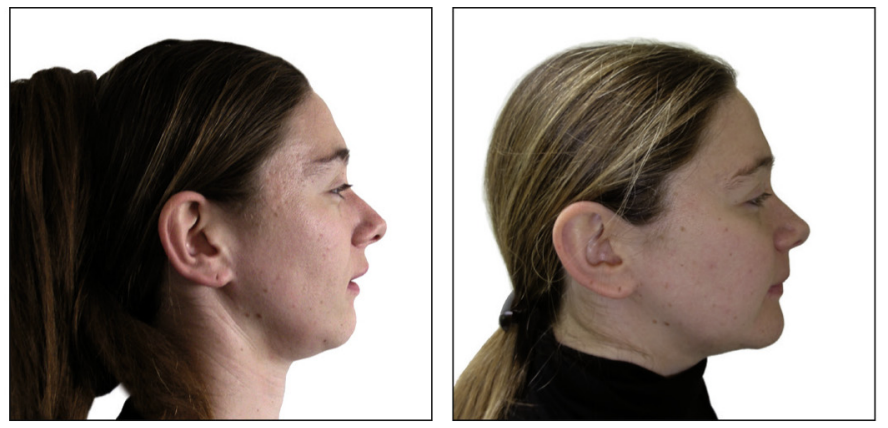

Natacha's case: no need for a genioplasty,...
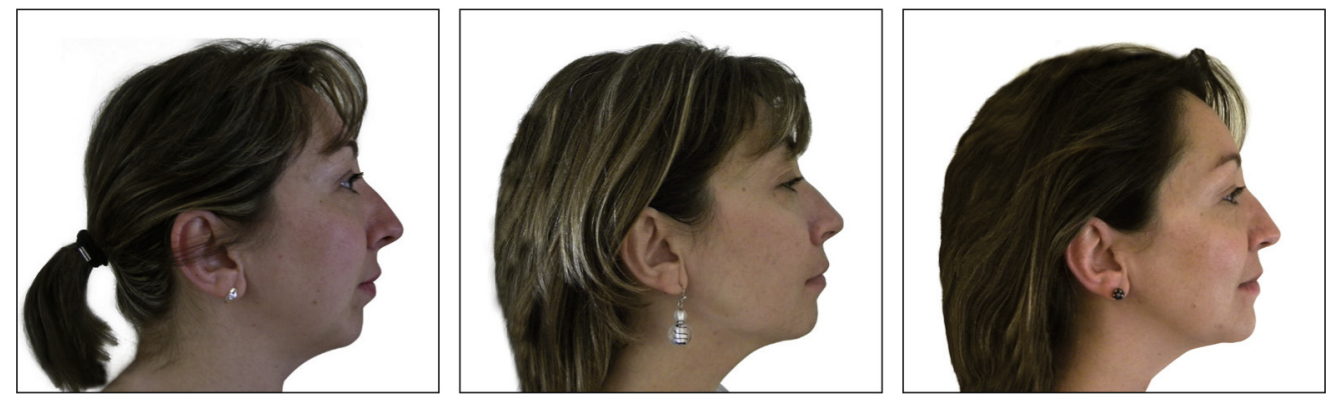

...Nathalie's case: performing a genioplasty more suitably adapted to the patient. 
condition will not be completely resolved by a treatment plan "without a genioplasty"

Given the number of parameters involved, the multitude of treatment plans that could be started (maxillary impaction, labioplasties, lingual retraining, improving nasal breathing, etc.) and the impossibility of predicting how the patient will respond to these treatments, we think it would be wise to defer the genioplasty procedure until after orthognathic surgery has taken place.

Even in cases where this procedure turns out to be necessary, the planning and the performing of the genioplasty as well as the results will be more accurate and more satisfying.

\section{DISCUSSION}

The matrix of this study takes into account the functional chin that is specific to humans.

- To the extent that the orthognathic surgery can restore this function: we provide the face with the opportunity "to create its own chin"

- If the functional context is obviously unfavorable: mentoplasty should immediately be planned.

\section{REFERENCES FOR CONSULTATION}

Beek M, Koolstra JH, van Ruijven LJ, van Ejden TM. 2000. Three-dimensional finite element analysis of the human temporomandibular joint disc. J Biomech 33:307-316.

Brace CL. 1979. Krapina, "Classic" Neanderthals, and the evolution of the European face. J Hum Evol 8:527-550

Choi SH, Cha JY, Kang DY, Hwang CJ. Surgical-orthodontic treatment for skeletal class II malocclusion with vertical maxillary excess, anterior open bite, and transverse maxillary deficiency. J Craniofac Surg. 2012;23(6):e531-5.

Daegling DJ. 1990. Geometry and biomechanics of hominoid mandibles, PhD Thesis, State University of New York at Stony Brook.

Daegling DJ. 1993. Functional morphology of the human chin. Evol Anthropol 1:170-177.

Daegling DJ. 2001. Biomechanical scaling of the hominoid mandibular symphysis. J Morphol 250:12-23.

Deshpande SN, Munoli AV. Osseous genioplasty: A case series. Indian J Plast Surg. 2011;44(3):414-21.

Dobson SD, Trinkaus E. 2002. Cross-sectional geometry and morphology of the mandibular symphysis in Middle and Late Pleistocene Homo. J Hum Evol 43:67-87.

DuBrul LE, Sicher H. 1954. The adaptive chin. Springfield: Charles C. Thomas.

Dumont ER, Grosse IR, Slater GJ. 2009. Requirements for comparing the performance of finite element models of biological structures. J Theor Biol 256:96-103.

Fagan MJ, Curtis N, Dobson CA, Karunanayake JH, Kupczik K, Moazen M, Page L, Phillips R, O'Higgins P. 2007. Voxelbased finite element analysis: working directly with microCT scan data. J Morphol 268:1071. 
Gröning F. 2009. The mechanical significance of anatomically modern human and Neanderthal mandibular morphology: a study using voxel-based finite element modelling, PhD Thesis, University of York, UK.

Gröning F, Fagan MJ, O'Higgins P. 2009a. Variation in mandibular morphology within late Homo and its relevance to masticatory load resistance. J Vertebr Paleontol 29 (Suppl): 109A.

Gröning F, Liu J, Fagan MJ, O'Higgins P. 2009b. Validationg a voxel-based finite element model of a human mandible using digital speckle pattern interferometry. J Biomech 42:1224-1229.

Gröning F, Liu J, Fagan MJ, O'Higgins, P. 2011. Why Do Humans Have Chins? Testing the Mechanical Significance of Modern Human Symphyseal Morphology With Finite Element Analysis, Am J Phys Anthropol 144:593-606.

Ho CT, Huang CS, Lo LJ. 2012. Improvement of chin profile after mandibular setback and reduction genioplasty for correction of prognathism and long chin. Aesthetic Plast Surg 2012 Oct;36(5):1198-206.

Hylander WL. 1984. Stress and strain in the mandibular symphysis of primates: a test of competing hypotheses. Am J Phys Anthropol 64:1-46.

Hylander WL. 1985. Mandibular function and biomechanical stress and scaling. Am Zool 25:315-330.

Hylander WL, Johnson KR. 1994. Jaw muscle function and wishboning of the mandible during mastication in macaques and baboons. Am J Phys Anthropol 94:523-547.

Hylander WL, Johnson KR. Crompton AW. 1987. Loading partterns and jaw mouvements during mastication in Macara fascicularis: a bone-strain, electromyographic, and cineradio graphic analysis. Am J Phys Anthropol 72:287-314.

Ichim I, Swain MV, Kieser JA. 2006a. Mandibular biomechanics and development of the human chin. J Dent Res 85:638-642.

Ichim I, Swain MV, Kieser JA. 2006b. Mandibular stiffness in humans: numerical predictions. J Biomech 39:1903-1913.

Jones ML, Hickman J, Middleton J, Knox J, Volp C. 2001. A validated finite element method study of orthodontic tooth movement in the human subject. J Orthod 28:29-38.

Koolstra JH, van Eijden TM. 2005. Combined finite-element and rigid-body analysis of human jaw joint dynamics. J Biomech 38:2431-2439.

Korioth TW, Hannam AG. 1994. Deformation of the human mandible during simulated tooth clenching. J Dent Res 73:56-66.

Korioth TW, Romilly DP, Hannam AG. 1992. Three-dimensional finite element stress anaIysis of the dentate human mandible. Am J Phys Anthropol 88:69-96.

Lam YM, Pearson OM, Smith CM. 1996. Chin morphology and sexual dimorphism in the fossil hominid mandible sample from Klasies River Mouth. Am J Phys Anthropol 100:545-557.

Lieberman DE. 1995. Testing hypotheses about recent human evolution from skulls: integrating morphology function, development, and phylogency. Curr Anthropol 36:159197.

Mandibula wing osteotomy for correction of the mandibular plane: A case report.

Triaca A, Minoretti R, Saulacic N. 2010. Br J Oral Maxillofac Surg 48(3):182-184.

Nalla RK, Kinney JH, Ritchie RO. 2003. Mechanistic fracture criteria for the failure of human cortical bone. Nat Mater 2:164-168.

Nelson GJ. 1986. Three dimensional computer modelling of the human mandibular biomechanics, MSc Thesis. Vancouver, Canada: University of British Columbia. 
O Connor Cf, Franciscus RG, Holton NE. 2005. Bite force production capability and efficiency in Neandertals and modern humans. Am J Phys Anthropol 127:129-151.

Ravosa MJ. 1991. Structural allometry of the prosimian mandibular corpus and symphysis. J Hum Evol 20:3-20.

Rayfield EJ. 2007. Finite element analysis and understanding the biomechanics and evolution of living and fossil organisms. Annu Rev Earth Planet Sci 35:541-576.

Reddy PS, Kashyap B, Hallur N, Sikkerimath BC. 2011. Advancement genioplasty-cephalometric analysis of osseous and soft tissue changes. J Maxillofac Oral Surg 10(4):288295.

Richmond BG, Wright BW, Grosse L, Dechow PC, Ross CF, Spencer MA, Strait DS. 2005. Finite element analysis in functional morphology. Anat Rec A Discov Mol Cell Evol Biol 283 A:259-274.

Richter M, Goudot P, Laurent F, Jaquinet A et Bidaut L. 1998. Chirurgie correctrice des malformations ou dysmorphies maxillomandibulaires: bases chirurgicales. Encycl Méd Chir (Elsevier, Paris), Stomatologie, 22-066-E-10, 24 p.

Sati S, Havlik RJ. 2011. An evidence-based approach to genioplasty. Plast Reconstr Surg 127(2):898-904.

Schwartz JH, Tattersall I. 2000. The human chin revisited: what is it and who has it? J Hum Evol 38:367-409.

Tanne K, Saduka M, Burstone CJ. 1987. Three-dimensional finite element analysis for stress in the periodontal tissue by orthodontic forces. Am J Othod Dentofacial Orthop 92:499-505.

Tanne K, Tanaka E, Sakuda M. 1991. The elastic modulus of the temporomandibular joint disc from adult dogs. J Dent Res 70:1545-1548.

Triaca A, Furrer T, Minoretti R. 2009. Chin shield osteotomy-a new genioplasty technique avoiding a deep mento-labial fold in order to increase the labial competence. Int $J$ Oral Maxillofac Surg 38(11):1201-1205.

Van Eijden TM. 2000. Biomechanics of the mandible. Crit Rev Oral Biol Med 11:123-136. 